\title{
A CFD study of turbulent heat transfer and fluid flow through the channel with semicircle rib
}

\begin{abstract}
In the present paper turbulent heat transfer and fluid flow through the channel with semicircle ribs numerically studied. The SST k- $\gamma$ turbulence Model with finite volume method was employed in simulation. The adopted boundary condition considered step heights of ribs varied from $2.5 \mathrm{~mm}$ to $10 \mathrm{~mm}$ with pitch ratio different from 2.5 to 40 and flow Reynolds number between 10000 to 25000 at constant surface temperature. The computational results showed recirculation region after each ribs which effect on performance of heat transfer rate. Increase of Reynolds number and number of ribs leads to increase in heat transfer coefficient. Step height and pitch ratio of ribs increase local heat transfer coefficient along the channel. This simulation has been done by ANSYS 14 FLUENT.
\end{abstract}

Keyword: Ribs conduit; Enhancement heat transfer; Turbulent flow; Recirculation flow 